\title{
A Violação dos Direitos Fundamentais das Crianças e a Reprodução da Violência Simbólica Por Meio dos Contos de Fada
}

\section{Vitoria Cândido Cardoso}

Faculdade de Direito de Vitória. vih-vih_candido@hotmail.com

\section{Cristina Grobério Pazó}

Faculdade de Direito de Vitória. crispazo@ uol.com.br

\section{Resumo}

Este artigo tem por objetivo analisar o impacto dos contos de fada no desenvolvimento da subjetividade da criança e do adolescente, bem como a consequente reprodução de padrões culturais eurocêntricos. São utilizados, para essa análise, conceitos estabelecidos por Pierre Bourdieu, como os de violência simbólica e habitus, entre outros. 0 artigo mostra a partir da análise da Constituição Federal e do Estatuto da Criança e do Adolescente a violação dos direitos fundamentais das crianças produzida pelos contos de fadas.

Palavras-chave: Violência simbólica. Contos de fada. Direito infanto-juvenil. Racismo. Padrões de beleza. 


\title{
The Violation of Childrens's Fundamental Rights and the Reproduction of Simbolyc Violence Though Fairy Tales
}

\begin{abstract}
This article's objective is to analyze the impact of Fairy Tales on the development of the personality of children and teenagers in addition to the reproduction of Eurocentric cultural patterns. For this essay, concepts established by Pierre Bourdieu, such as symbolic violence and habitus were used. The article also presents an assessment of the Brazilian law regarding children's rights and the violation of their fundamental rights through Fairy Tales.
\end{abstract}

Keywords: Symbolic violence. Fairy tales. Children's rights. Racism. Beauty standards.

Recebido em: 2/12/2016

Aceito em: 12/3/2017

\section{Sumário}

1 Introdução. 2 Violência simbólica e os conceitos de Pierre Bourdieu. 3 A legislação brasileira e a proteção da criança e do adolescente. 4 Contos de fada e o seu papel no desenvolvimento infantil. 5 Os contos de fada e a reprodução da violência simbólica. 6 Conclusão. 7 Referências. 


\section{INTRODUÇÃO}

A sociedade brasileira sempre teve dificuldade em admitir o teor danoso que muitas das práticas e costumes socialmente aceitáveis tiveram (e têm) sobre os grupos minoritários e especialmente à comunidade negra. Por gerações o racismo nacional se manteve inquestionado, acobertado pelo "mito da democracia racial". Ainda hoje perpetuam-se os efeitos de tal crença, principalmente por meio da reprodução acrítica de costumes que acabam por dar continuidade a tal pensamento.

Os contos de fada representam narrativas comumente utilizadas como ferramentas auxiliares no processo de desenvolvimento e aprendizado infantil, contribuindo para a formação de sua personalidade e sua visão de mundo, fornecendo não apenas lições que encorajem um comportamento positivo e virtuoso na criança, como também um meio mais brando para que elas tenham um contato inicial com conceitos como perda, morte e violência e possam conceber formas de lidar com eles.

Tais narrativas, no entanto, também podem apresentar significativa contribuição para a reprodução de preconceitos ou tradições danosas quando utilizadas de maneira desatenta.

A partir de uma análise da legislação dedicada a tratar sobre os direitos e as proteções destinadas a crianças e adolescentes, torna-se notável a violação ao artigo 227 da Constituição Federal em vigência ou ao Estatuto da Criança e do Adolescente (BRASIL, 1990).

Tais violações ocorrem, principalmente, a partir da perpetuação de violências simbólicas para com indivíduos que não se enquadrem no paradigma de beleza tipicamente europeu que é frequentemente reproduzido nessas narrativas. 
Dessa forma o presente trabalho tem como objetivo responder à seguinte indagação: Os contos de fada em regra estabelecem um padrão estético europeu. Em que medida esses contos contribuem para a perpetuação de violências simbólicas direcionadas a crianças negras e quais seriam as consequências jurídicas de tais violências?

Com o intuito de responder a tal indagação, foram trabalhados inicialmente os conceitos principais da obra de Pierre Bourdieu, a violência simbólica, habitus e campo. Subsequentemente foi realizada uma análise da legislação brasileira acerca da proteção conferida a crianças e adolescentes em âmbito nacional. Posteriormente ocorreu a avaliação do papel exercido pelos contos de fada no desenvolvimento subjetivo infantojuvenil e por fim foi avaliado o envolvimento que essas narrativas possuem no exército de violência simbólica contra infantes.

\section{VIOLÊNCIA SIMBÓLICA E OS CONCEITOS DE PIERRE BOURDIEU}

As últimas décadas trouxeram irrefutáveis questionamentos e desafios no âmbito social; concepções anteriormente tidas como corretas ou simplesmente naturais passaram a ser cada vez mais questionadas. Mais e mais grupos que anteriormente não possuíam visibilidade ao se manifestar passaram a protestar e lutar contra as violências e injustiças por eles sofridas.

Um notável exemplo desses avanços foi o movimento dos Direitos Civis realizado nos EUA. Esse movimento buscava a abolição das leis que permitiam a perpetuação da segregação racial no país. Tais leis eram conhecidas como "Jim Crow Laws", e vigoraram em múltiplos Estados norte-americanos entre 1876 e meados de 1960. Elencadas entre tais leis 
estavam, por exemplo, as que proibiam casamentos inter-raciais e a obrigação de criação de escolas diferentes para crianças brancas e negras (PILGRIM, 2012).

Apesar dos diversos avanços alcançados com esses movimentos, a discriminação racial direcionada a indivíduos negros foi e continua a ser uma prática em diversos países, incluindo o Brasil.

A História nacional apresenta um longo registro de preconceitos e opressões dirigidos à comunidade negra que, ao contrário do que certas crenças populares poderiam sugerir, continuou a enfrentar todo tipo de discriminação e exclusão após a assinatura da Lei Áurea. Desse modo,

Salta à vista que a conglomeração constante de certos indivíduos em lugares públicos acabou criando, tanto entre os "brancos" quanto entre os "negros", a convicção generalizada de que "o alcoolismo grassava em todos os recantos, levando o elemento negro à desgraça” [..] A visibilidade dos comportamentos em questão contribuiu, portanto, para que se exagerassem representações e avaliações que são parcialmente infundadas ou improváveis[..] (FERNANDES, 2008, p. 195).

E ainda:

A cordialidade com o "negro" não traduzia ausência pura e simples de distância social e de intolerância racial. Mas algo deveras mais complicado: a vigência de uma etiqueta de relações raciais que regulava, de forma extensa e firme, as atitudes e os comportamentos apropriados a cada circunstância [...] Se o "negro" deixasse de corresponder, de modo próprio, às expectativas convencionais, impunha-se "lhe dar uma lição", servindo seu almoço na cozinha ou se negando, abertamente, aquiescência as suas pretensões (FERNANDES, 2008, p. 351-352).

Apesar de notáveis avanços em relação ao passado, não é possível afirmar que a sociedade brasileira tenha abandonado por completo as práticas racistas e discriminatórias. Tais práticas são, ainda hoje, reiteradas 
por reproduções acríticas de tradições e padrões racistas presentes na cultura atual, que caracterizaria uma perpetuação mais sutil do preconceito, de maneira a tentar ocultar a violência infligida (MIRANDA, 2010, p. 12).

Uma dessas violências perpetuadas e sutilmente entrincheiradas em nossa cultura está intimamente ligada à aparência física. Tal comportamento não representa uma nova forma de violência, visto que pode ser observado desde a época da escravidão e da colonização, como exposto por Nilma Lino Gomes em:

A diferença impressa nesse mesmo corpo pela cor da pele e pelos demais sinais diacríticos serviu como mais um argumento para justificar a colonização e encobrir intencionalidades econômicas e políticas. Foi a comparação dos sinais do corpo negro (como o nariz, a boca, a cor da pele e o tipo de cabelo) com os do branco europeu e colonizador que, naquele contexto, serviu de argumento para a formulação de um padrão de beleza e de fealdade que nos persegue até os dias atuais (GOMES, 2002, p. 42).

Nesse contexto, torna-se evidente a importância da diferença existente entre os fenótipos tipicamente negros e os tipicamente brancos, principalmente em um contexto de dominação, no qual um se impôs como superior ao outro.

A partir desse cenário criam-se padrões e expectativas do que seria "bom" ou "ruim" dentro de uma sociedade, quais traços físicos seriam considerados "desejáveis" ou "belos" e quais seriam “odiosos” ou "feios”. A perpetuação de tais padrões também representa a manutenção de uma forma de violência que afeta principalmente as mulheres negras, à medida que

[...] pode-se argumentar que a mulher negra não é apenas considerada inferior, mas inimiga da beleza, é o mal encarnado na "antibeleza", a corrupção do padrão, o desvio, o erro, o pecado, o mal não apenas técnico, mas moral. Antimusa dá a ideia do oposto da perfeição estética 
e da inspiração superior da musa. Antimusa é a degradação mais completa, o polo oposto da beleza - a feiura (LOPES; SANT’ANA, 2014, p. $61)$.

Tal situação, essa valoração à primeira vista arbitrária, mas completamente normatizada dentro do contexto social, de um certo conjunto de atributos em detrimento de outros, pode ser fácil- mente compreendida com a aplicação dos conceitos definidos pelo sociólogo francês Pierre Felix Bourdieu, uma vez que ele se pôs a analisar o que chamou de violência simbólica e as dinâmicas sociais envolvidas na perpetuação dessa prática.

Entre os conceitos estabelecidos pelo autor, fundamentais para o entendimento de como tal violência opera é o que o autor chama de campo. Pode-se definir "campo" como um conjunto de espaços, não necessariamente físicos, ocupados por sujeitos e estruturados de tal forma que existam posições superiores e inferiores, e cujo tratamento do integrante desse grupo depende exclusivamente do espaço que ele ocupa na hierarquia, como exposto em:

Os campos apresentam-se à apreensão sincrônica como espaços estruturados de posições (ou de postos) cujas propriedades dependem da sua posição nesses espaços e que podem ser analisadas independentemente das características dos seus ocupantes (em parte determinadas por elas) (BOURDIEU, 2004, p. 119).

Os campos são fortemente marcados por sua conflitividade interna, uma vez que os integrantes de um mesmo campo buscam sempre acumular meios de ocupar posições mais elevadas na hierarquia interna do campo. Aqueles que já estão ocupando as posições mais elevadas lutam no sentido de preservar suas conquistas, são aqueles que por qualquer motivo ocupam as posições mais baixas que deverão, de fato, conquistar algo para si. Como esclarece Pierre Bourdieu: 
Os que, num estado determinado da relação de força, monopolizam (mais ou menos completamente) o capital específico, fundamento do poder ou da autoridade específica característica de um campo, inclinam-se para estratégias de preservação [...] ao passo que os menos providos de capital [...] inclinam-se para estratégias de subversão (2004, p. 121).

O chamado capital específico representa o que, dentro de certo campo, é valorado, e é uma das características que se altera dependendo do campo a ser analisado, podendo apresentar-se na forma de capital, objetos, títulos, traços físicos, etc.

Os campos possuem em si características muito particulares, sejam elas as regras de conduta, tipos de disputa ou as formas de acúmulo de capital específico. Para que um indivíduo integre as disputas internas é necessário que ele tenha um conhecimento preciso do funcionamento interno do campo, do significado interno de cada ato praticado, significados esses que não são percebidos por indivíduos externos ao campo. Dessa forma, para que um campo funcione efetivamente é necessário que existam sujeitos cientes de um conjunto de regras competindo pelo acúmulo de um certo capital específico de uma certa maneira. Tais disputas raramente fazem sentido para indivíduos que não estejam inseridos no contexto do campo (BOURDIEU, 2004, p. 120).

Uma das consequências naturais da inserção do indivíduo em um campo está no desenvolvimento de um habitus ligado àquele campo específico. "O habitus, como indica a palavra, é um conhecimento adquirido e também um haver, um capital (de um sujeito transcendental na tradição idealista), o habitus, a hexis, indica a disposição incorporada quase postural” (BOURDIEU, 2015, p. 60). 
Dessa maneira o indivíduo irá experimentar significativa melhora em sua eficiência para adquirir o capital específico com a incorporação do habitus, pois, ao incorporá-lo, o indivíduo estará tornando habituais, quase que involuntárias, as regras de conduta próprias do campo, sua lógica de funcionamento interna (BOURDIEU, 2004, p. 122).

Como já mencionado, os capitais específicos podem assumir qualquer forma, uma vez que têm o valor atribuído segundo as particularidades do campo em que se inserem. Nesse contexto, Marcelo Silva Ramos (2010), aponta para um tipo de capital específico identificado por meio de pesquisas no contexto carioca, o corpo:

$\mathrm{Na}$ atual sociedade de consumo, especializada em vender não apenas coisas, mas principalmente modelos de beleza, sucesso profissional, casamento, entre outros, defende-se os investimentos no corpo como garantia de ganhos nesses diferentes campos. As academias de musculação, os cirurgiões plásticos e dermatologistas, os produtos de higiene e beleza, os cosméticos, os alimentos light e diet, os inúmeros tratamentos e terapias corporais e as roupas de grife funcionam como aquelas aplicações financeiras que exigem alto investimento, mas que prometem uma valorização considerável desse importante capital, e também objeto de consumo, na nossa cultura: “o corpo” (p. 26).

Analisando o mesmo fenômeno do corpo como capital, Mirian Goldenberg (2010) aponta para o considerável aumento do número de cirurgias plásticas com finalidades estéticas no Brasil e para o aparente descontentamento constante, principalmente do público feminino, com sua aparência física. Ainda segundo esta autora:

Há uma construção cultural do corpo, com uma valorização de certos atributos e comportamentos em detrimento de outros, fazendo com que haja um corpo típico para cada sociedade. Esse corpo, que pode variar de acordo com o contexto histórico-cultural, é adquirido pelos 
membros da sociedade por meio da imitação prestigiosa. Os indivíduos imitam atos, comportamentos e corpos que obtiveram êxito e que têm prestígio em sua cultura (p. 45).

Sendo, portanto, o corpo (a pele, os olhos, cabelo, etc.) compreendido como um capital, a acumulação deste se dará a partir da aparência do indivíduo, se ele possui ou não os atributos corporais valorizados pelo contexto no qual está inserido. Esses atributos seriam, por exemplo, pele clara, cabelos lisos, olhos claros, corpo magro, seios fartos, quadris largos, etc. (GOLDENBERG, 2010).

Já o conceito de violência simbólica se traduz, de forma bem simples, em um tipo de violência que está atrelado aos conceitos de habitus e de campo, na medida em que não ocorre com o uso de agressão direta, seja ela física ou verbal. Ela ocorre a partir da interiorização das regras e dos costumes sociais. A partir desse cenário é esperado que certos grupos (mulheres, negros, etc.) apresentem um certo tipo de comportamento em relação a outros (homens, brancos, etc.), como esclarece Bourdieu ao analisar a questão:

Ela repousa sobre o que chamei de violência simbólica, ou seja, a violência que resulta do fato de as pessoas terem na cabeça princípios de percepção, maneiras de ver que são produto da relação de domínio. Dito de outra forma, elas colaboram, entre aspas, com sua própria dominação. Isso não significa que as mulheres sejam idiotas, fracas, ou submissas; quer dizer que as estruturas sociais levam-nas - desde a infância, na família, na escola - a incorporar, interiorizar um tipo de relação masculino-feminino através, por exemplo, do sistema de adjetivos [...] Tentei analisar tudo isso e mostrar que se trata de uma dominação muito difícil de ser modificada, pois não basta que se faça uma revolução econômica; é preciso também uma revolução simbólica nas cabeças. (Seria a mesma coisa no caso da dominação étnica entre brancos e negros) (BOURDIEU, 2002, p. 49). 
Dessa maneira, o autor estabelece que a violência simbólica serve como um meio de perpetuação da dominação de certos grupos por outros a partir do estabelecimento de valores simbólicos habituais e da reprodução acrítica desses valores em várias instâncias da sociedade. Esses valores podem ser instituídos de diversas maneiras.

O autor destaca, por exemplo, o sistema de adjetivos como uma maneira de reprodução desse tipo de violência, portanto não seria extraordinária a análise dos contos de fadas no sentido de detectar possíveis violências simbólicas reproduzidas por tais narrativas.

\section{A LEGISLAÇÃO BRASILEIRA E A PROTEÇÃO DA CRIANÇA E DO ADOLESCENTE}

O conceito de proteção aos entes ainda em desenvolvimento não é algo que seja absolutamente exclusivo ou novo a espécie humana. Mesmo diante de novas teorias e criticas vindas de pesquisadores que acreditam que o conceito atual de infância e a necessidade de proteger a prole sejam um mero fruto da modernidade um número considerável ainda defende a hipótese de que, mesmo no passado, cuidados especiais eram destinados os jovens membros da comunidade, uma vez que esses representavam seu futuro (ROCHA, 2002).

Atualmente o corpo legislativo nacional tem em seu conteúdo um rol de direitos e mecanismos de proteção diferenciados que são dedicados a resguardar a criança e o adolescente. A própria Carta Constitucional estabelece no caput de seu artigo 227 que é dever do Estado, da sociedade e da família prover para os jovens e crianças, de maneira que sejam assegurados seus direitos fundamentais, como liberdade e dignidade, além de garantir que tenham acesso à educação, cultura e lazer. 
Tal disposição traz consigo sinais de uma considerável mudança na mentalidade nacional, uma vez que nenhum texto constitucional havia anteriormente dedicado tal atenção especificamente à proteção dos direitos infantojuvenis, como apontam Maria Celina Bodin de Morais e Ana Carolina Brochado Teixeira (2013):

O art. 227 da Constituição Federal de 1988 é fruto de uma "virada hermenêutica” sobre a concepção da relevância dos direitos da criança e do adolescente. Tanto que é inovador quanto ao tratamento da população infantojuvenil por uma Constituição, pois dedica à criança e ao adolescente um dos mais expressivos textos consagradores de direitos fundamentais da pessoa humana, cujo conteúdo foi, posteriormente, explicitado pelo Estatuto da Criança e do Adolescente, Lei 8.069/1990 (v. art. $\left.3^{\circ}\right)$ (p. 4.610).

É possível concluir então, como foi apontado pelas autoras, a importância do artigo 227 da Constituição Federal Brasileira como diretriz a ser seguida por todo o ordenamento infraconstitucional, sendo tal artigo fundamental para a proteção da dignidade das crianças e dos adolescentes e, por conseguinte, para salvaguardar seus direitos fundamentais (MORAIS; TEIXEIRA, 2013, p. 4.613).

Tal dispositivo ainda possui uma importância que se estende para além do que foi anteriormente exposto, uma vez que, segundo Luciano Alves Rossato, Paulo Eduardo Lépore e Rogério Sanches Cunha, no texto desse enunciado encontra-se a base para a extração para o que eles chamam meta princípio da prioridade absoluta dos direitos da criança e do adolescente, que atuaria da seguinte maneira:

Pretende, pois, que a família se responsabilize pela manutenção da integridade física e psiquiátrica, a sociedade pela convivência coletiva harmônica, e o Estado pelo constante incentivo à criação de políticas públicas. Trata-se de uma responsabilidade que, para ser realizada necessita de uma integração, de um conjunto devidamente articulado de políticas públicas. Essa competência difusa, que responsabiliza uma 
diversidade de agentes pela promoção da política de atendimento à criança e ao adolescente, tem por objetivo ampliar o próprio alcance da proteção dos direitos infantojuvenis (ROSSATO; LÉPORE; CUNHA, 2014, p. 74).

Além do dispositivo constitucional anteriormente citado, os direitos e interesses das crianças e adolescentes também encontram-se amparados na Lei 8.069/1990, ou Estatuto da Criança e do Adolescente, além da Convenção Sobre os Direitos da Criança, que foi acolhida pelo ordenamento nacional a partir do Decreto Legislativo $\mathrm{n}^{0}$ 99.210, de 21 de novembro de 1990.

Tanto o artigo 227 da Constituição Federal quanto o Estatuto da Criança e do Adolescente e a Convenção Sobre os Direitos da Criança são marcos do avanço na luta pelo reconhecimento desses indivíduos que não apenas necessitam de cuidado passivamente, mas como detentores de direito, que, por se encontrarem em delicada fase de desenvolvimento, possuem necessidades únicas.

Embora exista muita discussão acerca do método utilizado para estabelecer os marcos divisores entre uma criança, um adolescente e um adulto, como lembra Wilson Donizeti Liberati (2003), o método adotado pela legislação nacional baseia-se em um conceito puramente cronológico, sendo considerada uma criança toda pessoa que tenha até 12 anos incompletos e um adolescente todo aquele que tiver até 18 anos de idade.

Esses indivíduos requerem especial atenção por parte de sua comunidade, uma vez que se encontram em seu período de desenvolvimento e a exposição a um ambiente demasiadamente negativo ou que não forneça as ferramentas adequadas para seu crescimento podem acarretar sérios danos, como exposto por Dallari e Korczak (1986):

O desenvolvimento da inteligência, da vontade e da sensibilidade é que irá definir a forma de integração da criança na comunhão humana. Mais tarde a sociedade exigirá que a criança seja um adulto bem integrado, 
capaz de usar de modo benéfico, favorável às outras pessoas, todos esses atributos, mas é preciso ter em conta que nos primeiros anos, que são o momento decisivo de seu desenvolvimento, tais atributos dependem muito mais dos outros do que da própria criança. Por isso é absolutamente necessário que desde o seu primeiro instante de vida a criança seja reconhecida como pessoa e tratada como tal, pois na realidade ela é uma pessoa, que se tiver condições favoráveis poderá desenvolver todas as suas potencialidades e contribuir para o bem-estar e aperfeiçoamento da humanidade (p. 22-23).

Como já referido, é de extrema importância garantir a preservação de todos os direitos das crianças e adolescentes, uma vez que a exposição a um ambiente preconceituoso, opressivo ou tóxico de qualquer maneira pode vir a impactar negativamente todo o seu processo de desenvolvimento, o que pode representar uma perda significativa, ou em complicações que se prolongarão no tempo indefinidamente.

Nesse contexto é importante ressaltar que a legislação nacional optou por adotar a chamada doutrina da proteção integral da infância e da adolescência, tal qual está exposto no artigo $1^{0}$ do Estatuto da Criança e do Adolescente. Interpretação essa que decorreu da tentativa de elevar ao máximo a eficácia dos direitos fundamentais garantidos às crianças e adolescentes pelo texto constitucional, assim como os direitos que já haviam sido afirmados em diversos tratados internacionais (ROSSATO; LÉPORE; CUNHA, 2014).

Tal posicionamento parte do pressuposto de que a criança e o adolescente passam a ser reconhecidos como sujeitos de direitos próprios, direitos esses que são independentes da vontade dos familiares ou do próprio Estado, não sendo portanto meros objetos passivos da vontade de seus cuidadores. São eles titulares de todos os direitos fundamentais comuns a todo indivíduo, e além disso, por conta do período de desenvol- 
vimento no qual se encontram, possuem certos direitos especiais, como a prioridade a eles garantida pelo texto constitucional em seu artigo 229 (CURY; PAULA; MARÇURA, 2002).

A legislação nacional mostra-se extremamente preocupada com o resguardo desse conjunto de direitos, tendo sido o Estatuto da Criança e do Adolescente elaborado com o intuito de oferecer uma proteção mais segura aos indivíduos que ainda não completaram seu período de desenvolvimento.

Indo ao encontro de tal noção o artigo $3^{\circ}$ do próprio Estatuto estabelece que os jovens e infantes devem ter todos os direitos fundamentais, naturais de todo ser humano, respeitados, assim como devem ter acesso a meios e oportunidades para o seu sadio crescimento e desenvolvimento, seja ele físico, moral ou espiritual, sendo sempre observado seu direito à liberdade e à dignidade.

Ainda nesse sentido o artigo $7^{\circ}$ do Estatuto não dispõe apenas sobre a vida como condição biológica, mas sobre a proteção integral de todas as possíveis dimensões do direito à vida, seja na proteção da sua permanência, da integridade do corpo e da mente ou a integridade moral do indivíduo, uma vez que valores imateriais, como a moral, também podem ser considerados integrantes do conjunto (ROSSATO; LÉPORE; SANCHES, 2014).

O Estatuto dedica um dispositivo específico ao resguardo da intimidade, identidade e dos valores desses indivíduos, o artigo 17, uma vez que estamos nos referindo a indivíduos inseridos em delicado processo de formação, a proteção desse direito mostra-se potencializada, haja vista que por estarem inseridos nesse contexto estão em situação de considerável fragilidade, e os danos sofridos pela violação dessas proteções são muito mais severos, podendo perdurar por toda a vida do indivíduo (ROSSATO; LÉPORE; SANCHES, 2014). 
Diante de tudo que foi exposto até agora entende-se que a legislação nacional busca de todas as formas possíveis assegurar o sadio desenvolvimento de crianças e adolescentes, vedando que sejam expostos a qualquer situação ou ambiente que possa potencialmente vir a causar prejuízos tanto físicos quanto psíquicos em sua vida adulta.

Tendo tal conceito em mente surge a difícil tarefa de proporcionar um ambiente no qual infantes e adolescentes não se encontrem expostos a preconceitos e discriminações que podem lhes causar irreparáveis prejuízos.

A exposição a práticas preconceituosas, por exemplo, o racismo, contribui para a sua perpetuação, causando consideráveis impactos ao desenvolvimento desses indivíduos de forma que mesmo que sua presença seja indireta, a sua mera presença no processo de socialização, seja ele no seio familiar ou no contexto escolar, já causa considerável impacto à subjetividade, das crianças em especial, e podem passar a influenciar suas relações sociais pelo restante da vida (MIRANDA, 2010).

As próprias instituições de ensino que deveriam proporcionar ambiente propício a interações positivas e a desconstrução de preconceitos negativos adquiridos em outros contextos acabam de alguma forma contribuindo para a propagação de comportamentos danosos, como aponta Nilma Lino Gomes:

A escola impõe padrões de currículo, de conhecimento, de comportamentos e também de estética. Para estar dentro da escola é preciso apresentar-se fisicamente dentro de um padrão, uniformizar-se. A exigência de cuidar da aparência é reiterada, e os argumentos para tal nem sempre apresentam um conteúdo racial explícito. Muitas vezes esse conteúdo é mascarado pelo apelo às normas e aos preceitos higienistas (2002, p. 45). 
Dessa forma, ao invés de proporcionar um espaço fértil para a desconstrução o ambiente escolar torna-se mais um local de reprodução desses ideais, permitindo que os jovens cresçam sem realizar um profundo questionamento dessas ideias e submetendo os alunos negros a constrangimentos e opressões, que se tornam amplamente danosos à constituição de sua identidade como negros e a sua autoestima.

Para essas pessoas, na sua maioria mulheres negras jovens e adultas, na faixa dos 20 aos 60 anos, a experiência com o corpo negro e o cabelo crespo não se reduz ao espaço da família, das amizades, da militância ou dos relacionamentos afetivos. A trajetória escolar aparece em todos os depoimentos como um importante momento no processo de construção da identidade negra e, lamentavelmente, reforçando estereótipos e representações negativas sobre esse segmento étnico/racial e o seu padrão estético (GOMES, 2002, p. 41).

Ainda de acordo com Gomes (2002), mulheres negras de diversas idades sofreram experiências negativas relacionadas a seu fenótipo durante o período escolar.

Diante de tais fatos é notável a situação de violação de direitos, uma vez que um grupo de crianças e adolescentes encontram-se expostos a um contexto que se mostra claramente prejudicial para que se desenvolvam de maneira sadia e harmoniosa, estando inseridos em situações em que sua dignidade e a integridade de suas mentes, seus corpos, ficam comprometidas.

\section{CONTOS DE FADA E O SEU PAPEL NO DESENVOLVIMENTO INFANTIL}

Através dos séculos os grupos de seres humanos têm se juntado e contado histórias uns aos outros, seja como forma de perpetuar a cultura, seja a fim de ensinar a uma nova geração os valores e lições consideradas importantes naquele meio. 
Entre essa miríade de histórias os chamados contos de fada destacam-se das demais. Rodolpho Alexandre Santos Melo Bastos e Joanna Ribeiro Nogueira (2016) alertam que tais contos possuem determinadas semelhanças, estando entre elas

uma narrativa na qual o personagem central deve enfrentar grandes obstáculos, passando por diversas provações antes de triunfar contra 0 mal. Tais narrativas transferem o leitor para um mundo imaginário, mas ainda assim pautado em elementos do seu cotidiano, como os valores morais e os ideais de bondade e maldade. Além disso, os contos de fada evocam sentimentos como medo, amor, ódio e simpatia através de uma jornada que envolve conflitos, rivalidade e superação, convidando o leitor a experimentar a sensação de um final feliz, transferindo essa expectativa para sua experiência individual (p. 12).

Já Bruno Bettelheim (2002) delimita um conceito um pouco mais fechado para o que poderia ser considerado um conto de fada, uma vez que ele atribuía a essas histórias importante papel no desenvolvimento infantil:

Através da maior parte da história da humanidade, a vida intelectual de uma criança, fora das experiências imediatas dentro da família, dependeu das estórias míticas e religiosas e dos contos de fadas. Esta literatura tradicional alimentava a imaginação e estimulava as fantasias. Simultaneamente, como estas estórias respondiam às questões mais importantes da criança, eram um agente importante de sua socialização. Os mitos e as lendas religiosas mais intimamente relacionadas ofereciam um material a partir do qual as crianças formavam os conceitos de origem e propósito do mundo, e dos ideais sociais que a criança podia buscar como padrão (2002, p. 24).

Nesse sentido, Bettelheim (2002) acreditava que o processo de identificação e aprendizado com tais histórias era fundamental para o saudável desenvolvimento infantil, uma vez que elas permitiam que as crianças entrassem em contato com situações como a morte, o abandono, 
o guardião abusivo e a partir do que é exposto nesses contos a criança seria capaz de construir soluções e adquirir a maturidade necessária para seu desenvolvimento pessoal. Afirma ele:

Através dos séculos (quando não dos milênios) durante (sic) cquais os os contos de fadas, sendo recontados, foram-se tornando cada vez mais refinados, e passaram a transmitir ao mesmo tempo significados manifestos e encobertos - passaram a falar simultaneamente a todos os níveis da personalidade humana, comunicando de uma maneira que atinge a mente ingênua da criança tanto quanto a do adulto sofisticado. Aplicando o modelo psicanalítico da personalidade humana, os contos de fadas transmitem importantes mensagens à mente consciente, à pré-consciente, e à inconsciente, em qualquer nível que esteja no momento. Lidando com problemas humanos universais, particularmente os que preocupam o pensamento da criança, estas estórias falam ao ego em germinação e encorajam seu desenvolvimento, enquanto ao mesmo tempo aliviam pressões pré-conscientes e inconscientes. À medida que as estórias se desenrolam, dão validade e corpo às pressões do id, mostrando caminhos para satisfazê-las, que estão de acordo com as requisições do ego e do superego (p. 6).

Em sentido semelhante Bastos e Nogueira (2016) concordam com a importância de tais narrativas no processo de aprendizado infantil, uma vez que elas representam maneiras para que as crianças fiquem imersas em fantasias, se divirtam e ao mesmo tempo se familiarizarem com conflitos como medo, amor, abandono, autodescoberta e muito mais.

Ao contrário de Bettelheim (2002), porém, não consideram os contos de fada como sendo uma presença unicamente positiva no desenvolvimento infantil, pois eles trariam consigo, em seu texto, uma bagagem que estaria atrelada à visão de mundo existente em sua época e país de origem, contribuindo, por exemplo, para a perpetuação de estereótipos ligados ao gênero, como o arquétipo da donzela em perigo, da princesa delicada ou da madrasta invejosa. 
Dessa forma, Bastos e Nogueira (2016) advertem para o potencial perigo que a reprodução desatenta de um desses contos por um educador

pode vir a representar. É possível notar que mesmo que não atribuam a mesma importância defendida por Bettelheim (2002), estão cientes de que tais narrativas têm um papel delicado no desenvolvimento das crianças.

\section{OS CONTOS DE FADA E A REPRODUÇÃO DA VIOLÊNCIA SIMBÓLICA}

Como já foi anteriormente apontado, os contos de fada desempenham um delicado papel no processo de aprendizado e de socialização das crianças, uma vez que representam as narrativas às quais elas são quase que constantemente expostas.

Por esse motivo é extremamente importante pensar no impacto que tais narrativas possam vir a ter, direta ou indiretamente, no desenvolvimento do olhar dessas crianças sobre o mundo e sobre si mesmas.

É comum que esses contos tragam como protagonista uma "bela princesa” ou um "galante príncipe”, e como antagonistas “irmãs feias” ou "bruxas invejosas”. É ainda bem usual que os protagonistas sejam associados com todo tipo de virtude, enquanto os antagonistas representam tudo que há de repulsivo.

Isso ocorre em geral para que a criança sinta mais simpatia pelos protagonistas e não sinta qualquer tipo de simpatia pelos antagonistas, para que ela entenda que aqueles representam o modelo de tudo que elas deveriam aspirar a ser, e esses o que elas deveriam a todo custo evitar (MIRANDA, 2010).

A existência simples e pura desse tipo de estrutura narrativa não cria, exatamente, problemas por si só, porém ao abrir um livro de contos de fada logo somos confrontados com um sério problema. Neles geral- 
mente as protagonistas, comumente associadas à beleza, quase sempre exibem caraterísticas físicas brancas, como cabelos e olhos claros, nariz fino e pequeno, além da pele pálida.

Essa informação torna-se ainda mais relevante a partir do que é exposto nos estudos sobre o racismo, a estética e a subjetividade em contos de fada, pois

as crianças, no geral, associaram, assim como a beleza, várias virtudes como sendo naturais às boas princesas, aspectos como delicadeza, inteligência, elegância, bondade, etc.[...]. Além desses aspectos a descrição de uma princesa bonita também contemplava bons comportamentos que são reforçados pelos pais, tais como cuidar da higiene, ser carinhosa, ajudar os outros, ser educada e limpa. (MIRANDA, 2010, p. 21).

As crianças, portanto, que ainda estão descobrindo o mundo e procurando seu lugar nele, passam a associar essas virtudes inerentes às princesas com a aparência que estas trazem. A falta de representatividade, nesse caso, dificulta a associação de traços tipicamente africanos com essas virtudes.

Tal realidade é especialmente visível em se tratando do cabelo, pois já inicialmente nas histórias infantis o cabelo liso é constantemente atrelado ao belo. Destaca-se, ainda, que a caracterização do cabelo das princesas é muitas vezes parte relevante de suas histórias, uma vez que não haveria Rapunzel sem suas “tranças cor de mel” e a Cachinhos Dourados sequer tem um nome, sendo identificada apenas pela sua linda cabeleira.

A violência simbólica relacionada a essa caraterística estética não termina na falta de representatividade positiva em contos infantis, ela também se traduz em insultos no cotidiano: "cabelo duro" e "Bombril” são alguns dos apelidos atribuídos a pessoas que possuam os cabelos crespos. 
A reprodução desse tipo de narrativas agrega valor a uma certa combinação de traços físicos, e quando não ignora, geralmente denigre a outra; já desde a infância o cabelo loiro e liso, ou com enormes cachos, olhos de coloração clara, azul ou verde, e um corpo esguio tornam-se um tipo de capital que deve ser adquirido por meio do uso de produtos de beleza e tratamentos químicos.

Aquelas que não se submeterem a tais padrões estarão sujeitas a todo tipo de violência, seja ela simbólica, na forma de exclusão social, insultos, etc., ou mesmo violência física por parte de terceiros.

A reprodução acrítica desses contos serve para a manutenção do status quo existente, de forma que incute já muito cedo na cabeça das jovens um padrão de beleza decididamente eurocêntrico, com suas princesas de pele branca como a neve e cabelos dourados como a aurora.

Tal violência pode passar despercebida pela maioria, não apenas por seu caráter simbólico, pois a ação pedagógica exercida pelos pais e educadores ao se utilizarem de tais contos como ferramentas para auxiliar no ensino dos jovens tem como principal característica a reprodução da cultura dominante, assegurando que aqueles que se desviam do padrão por ela (arbitrariamente) estabelecido sejam ou submetidos a violências até que se adaptem ao padrão, ou sejam considerados indivíduos desviantes, reprodutores de uma cultura ilegítima (BOURDIEU; PASSERON, 2009).

\section{CONCLUSÃO}

A reprodução acrítica e quase que exclusiva de narrativas e contos de fadas que reiteram um padrão de beleza eurocêntrico acaba por submeter as crianças negras a violências simbólicas, que podem acarretar sérias consequências com o decorrer do tempo, pois os indivíduos submetidos a tal violência podem acabar por assimilar que sua aparência natural, pele 
escura e cabelos crespos, mais especificamente, realmente possui valor inferior a uma aparência física mais próxima da europeia, cabelos claros e pele branca.

Diante de tal situação já é possível identificar clara violação dos direitos da criança e do adolescente, uma vez que a sua exposição a tal ambiente acaba proporcionando uma variedade de malefícios. Elas têm sua autoestima claramente prejudicada, uma vez que já no início de seu processo de desenvolvimento não são incentivadas a associar seu reflexo com o belo ou o bom, mas, nas poucas circunstâncias em que se faz presente, com o mal e o sujo.

Por conta disso é necessário que seja dedicada mais atenção à importante fase que constitui o período de desenvolvimento principalmente da infância, para que posturas acríticas não sejam reiteradas e a continuidade da reprodução da violência simbólica seja amenizada, permitindo que seja construído um ambiente amplamente saudável, favorável para o adequado amadurecimento de crianças e adolescentes como foi previsto pelo ordenamento, representando o ambiente escolar uma área fundamental à composição de tal espaço.

O texto legal nacional determina como obrigação conjunta do Estado e da sociedade garantir a proteção dos direitos fundamentais dessa parcela da população. Dessa maneira, é dever do Estado realizar a manutenção dos espaços educacionais de forma a garantir a eficácia dos direitos supracitados.

\section{REFERÊNCIAS}

BASTOS, R. A. S. M.; NOGUEIRA, J. R. Estereótipos de gênero em contos de fada: uma abordagem histórico-pedagógica. Dimensões: Revista de História da Ufes, Espírito Santo, n. 36, p. 12-30, jan./jun. 2016. 
BETTELHEIM, B. A psicanálise dos contos de fadas. 16. ed. Rio de Janeiro: Paz e Terra, 2002.

BRASIL. Constituição [da] República Federativa do Brasil. Disponível em: $<$ https://www.planalto.gov.br/ccivil_03/constituicao/constituicao.htm>. Acesso em: 5 nov. 2016a.

. Lei no 8.069/1990. 1990. Disponível em: <https://www.planalto.gov. br/ccivil_03/leis/L8069.htm>. Acesso em: 5 nov. 2016.

. Decreto Lei $n^{\circ}$ 99.710/1990. Disponível em: <http://www.planalto. gov.br/ccivil_03/decreto/1990-1994/D99710.htm>. Acesso em: 5 nov. 2016b. BOURDIEU, P. O poder simbólico: (história \& sociedade). 2. ed. Lisboa: Edições 70, 2015.

Questões de sociologia. 2. ed. Lisboa: Fim de Século, 2004.

. Pierre Bourdieu entrevistado por Maria Andrea Loyola. Rio de Janeiro: Eduerj, 2002.

BOURDIEU, P.; PASSERON, Jean-Claude. A reprodução: elementos para uma teoria do sistema de ensino. Corvilhã: Universidade da Beira Interior, 2009.

CURY, M.; PAULA, P. A.; MARÇURA, J. N. Estatuto da Criança e do Adolescente Anotado. 3. ed. São Paulo: Revista dos Tribunais, 2002.

DALLARI, D. A; KORCZAK, J. O direito da criança ao respeito. 3. ed. São Paulo: Summus, 1986.

FERNANDES, F. A integração do negro na sociedade de classes: o legado da “raça branca”. 5. ed. São Paulo: Globo, 2008. V. 1.

GOLDENBERG, M. (Org.). O corpo como capital. In: . O corpo como capital. 2. ed. São Paulo: Estação das Letras e Cores, 2010. p. 39-53.

GOMES, N. L. Trajetórias escolares, corpo negro e cabelo crespo: reprodução de estereótipos ou ressignificação cultural? Revista Brasileira de Educação, Rio de Janeiro, n. 21, set./out./nov./dez. 2002. Disponível em: <http://www. scielo.br/pdf/rbedu/n21/n21a03>. Acesso em: 31 maio 2016. 
LIBERATI, W. D. Comentários ao Estatuto da Criança e do Adolescente. 7. ed. rev. ampl. São Paulo: Malheiros Editores, 2003.

LOPES, C. R.; SANT'ANA, J. V. B. A imagem do negro em produtos de beleza e a estética do racismo. In: SEMINÁRIO DE ENSINO, PESQUISA E EXTENSÃO NA GRADUAÇÃO, 2., 2014, Campos Belos. Anais... Campos Belos, 2014. Disponível em: <http://www.anais.ueg.br>. Acesso em: 31 maio 2016.

MIRANDA, Debora Brasil. Princesas de contos de fadas e crianças negras: racismo, estética e subjetividade. 2010. Trabalho de Conclusão de Graduação em Psicologia - Universidade Católica de Brasília, 2010. Disponível em: $<$ https://xa.yimg.com/kq/groups/87025604/1872927713/name/RERprinc esas+de+contos+de+fada+e+criancas+negras.pdf $>$. Acesso em: 31 maio 2016. MORAIS, M. C. B.; TEIXEIRA, A. C. B. Comentário ao artigo 227. In: CANOTILHO, J. et al. (Coord.). Comentários à Constituição do Brasil. São Paulo: Saraiva; Almedina, 2013. p. 4.606-4.634.

PILGRIM, D. What was Jim Crow. 2012. Jim Crow Museum. Ferris Satate University. Disponível em: <http://www.ferris.edu/jimcrow/what.htm>. Acesso em: 31 maio 2016.

RAMOS, M. S. O corpo como capital e a felicidade. In: GOLDENBERG, Mirian (Org.). O corpo como capital. 2. ed. São Paulo: Estação das Letras e Cores, 2010. p. 19-28.

ROCHA, R. C. L. História da infância: reflexões acerca de algumas concepções correntes. Analecta, Paraná, v. 3, n. 2, p. 51-63, jul./dez. 2002.

ROSSATO, L. A.; LÉPORE, P. E.; CUNHA, R. S. Estatuto da Criança e do Adolescente. 6. ed. rev. atual. ampl. São Paulo: Revista dos Tribunais, 2014. 